Article

\title{
The Development and Assessment of Free-Flow Speed Models under Heterogeneous Traffic in Facilitating Sustainable Inter Urban Multilane Highways
}

\author{
Lee Vien Leong ${ }^{1, *} * \mathbb{D}$, Tuti Azmalia Azai ${ }^{2}$, Wins $\operatorname{Cott}$ Goh $^{3}$ and Mohammed Bally Mahdi ${ }^{4}(\mathbb{C}$ \\ School of Civil Engineering, Engineering Campus, Universiti Sains Malaysia, Nibong Tebal 14300, Malaysia \\ City Council of Penang Island, Penang 10675, Malaysia; tutiazmalia@mbpp.gov.my \\ Intelliroad Services, 25-2, Menara Promenade, 189 Jalan Tun Razak, Kuala Lumpur 50400, Malaysia; \\ intelliroad@gmail.com \\ 4 Civil Engineering Department, College of Engineering, Al Muthanna University, Samawah 66001, Iraq; \\ engmohbaly@gmail.com \\ * Correspondence: celeong@usm.my
}

Received: 20 March 2020; Accepted: 10 April 2020; Published: 23 April 2020

check for updates

\begin{abstract}
The desired speed that drivers can drive without being obstructed or influenced by other road users is characterized as free-flow speed. However, free-flow speed can be influenced by other factors such as the characteristics of the vehicle, driver, road conditions, weather, and speed limits. Due to the country's heterogeneous traffic conditions, this study aims to develop and assess free-flow speed models based on different vehicle classes and road characteristics in Malaysia. Data were sampled at 16 sites of multilane highways in Malaysia. Analyses of free-flow speed were conducted based on individual and grouped vehicle classes. Subsequently, multiple regression analyses were conducted based on these grouped vehicle classes to develop free-flow speed models. The findings show that the model with the grouping of all vehicles, which includes heavy vehicles and motorcycles, is the most suitable model as it yields the best results based on the performance indicators. The development of a free-flow speed model based on local traffic conditions, which can accurately estimate free-flow speed without having to conduct field measurements, is essential for saving time and costs in data collection. The findings from this study will contribute to improving the design of multilane highways and, ultimately, ensuring the sustainable environment of road networks.
\end{abstract}

Keywords: free-flow speed; multilane highways; heterogeneous traffic; vehicle classifications

\section{Introduction}

Multilane highways are highways with more than one lane in each direction. These highways can be undivided or divided. Divided multilane highways in Malaysia are typically located in urban and suburban areas due safety reasons where turning is not allowed under high traffic conditions. Divided highways are separated with a rigid or flexible barrier. These barriers may be paved or use a landscape median that separates each direction. Multilane highways usually have posted speed limits between 60 to $90 \mathrm{~km} / \mathrm{h}$. In Malaysia, these highways usually have two lanes in each direction and are typically located in suburban communities that lead into central cities. They may also extend along high-volume rural corridors, connecting two cities or two significant activities that generate a substantial number of daily trips. According to the Malaysian road geometry design guidelines [1], urban areas are defined as areas with a population of at least 10,000 people, where buildings and houses are gathered, and business activities are prevalent. This term covers all areas within the gazetted municipality limits, 
which includes areas that are expected to become urbanized within the design period. Rural areas, on the other hand, are areas other than urban areas. The rural standard for Malaysian highways is designed according to the R5 standard. The R5 standard is the design standard for roads, provides a high geometric standard, and usually serves long to intermediate trip lengths with high to median traveling speeds and partial access control [1].

Free-flow speed is defined as the desired speed at which drivers feel comfortable to travel under physical, environmental, and traffic control conditions on uncongested segments of the highway [2]. The free-flow speed of multilane highways can be determined directly from speed studies conducted in the field, and the field-measured free-flow speed is the mean speed of passenger cars under low-to-moderate traffic flow. According to U.S. Highway Capacity Manual (HCM) 2010, the upper limit of the low volume of multilane highways is 1400 passenger cars per hour per lane $(\mathrm{pcu} / \mathrm{h} / \mathrm{ln})$, which can be determined either as a space mean or as a time mean speed [2]. The time mean speed is the arithmetic mean of individual speeds, while the space-mean speed is the harmonic mean. However, the applications of space mean speed are more extensive, and this type of speed is the basis for many planning models used to estimate the average travel speed and capacity [2,3].

Tseng et al. [4] stated that free-flow speed is the speed of a vehicle when the vehicle's movement is not interfered by other vehicles or interrupted by control devices. In a study in Taiwan, the free-flow speed of vehicles was measured with a laser gun at the midpoint of each segment under fair weather conditions, and the vehicles were classified into small vehicles, large vehicles, and motorcycles. Only vehicles that were separated by headways of more than $5 \mathrm{~s}$ were sampled to ensure that the data were obtained under very light flow conditions. Bang et al. [5], however, stated that free-flow speed should be determined for unobstructed vehicles based on the definition of the vehicles with headway to the nearest vehicle in front of more than $8 \mathrm{~s}$ and no recent or immediate meeting with a vehicle in the opposing direction. Nevertheless, according to Boora et al. [6], for heterogeneous traffic conditions on multilane highways, a gap is more suitable to use than a headway as a gap does not vary due to vehicle length. A new measure called "Speed Difference" was introduced by Boora et al. and was found to be suitable for identifying the free-flow conditions. Nonetheless, in a study conducted by Dixon et al. [7], free-flow speeds were determined based on the 85th-percentile speed or the posted speed limit. This past study observed the influence of speed limits of $88.6 \mathrm{~km} / \mathrm{h}(55 \mathrm{mi} / \mathrm{h})$ and $104.7 \mathrm{~km} / \mathrm{h}(65 \mathrm{mi} / \mathrm{h})$ on free-flow speed and the posted speed limit on rural multilane highways in Georgia. The 85-percentile speed is the speed at or below which $85 \%$ of all vehicles are observed to travel under free following conditions. The authors found that the posted speed limits of $88.6 \mathrm{~km} / \mathrm{h}(55 \mathrm{mi} / \mathrm{h})$ and $104.7 \mathrm{~km} / \mathrm{h}$ $(65 \mathrm{mi} / \mathrm{h})$ directly influenced the free-flow speed, and an increase in the posted speed limit resulted in an increased operating speed. Deardoff et al. [8] also found that the average free-flow speeds have a strong and significant association (with a correlation coefficient of +1.00 ) with the posted speed limits, and the study conducted by Ali et al. [9] on urban roads in Virginia also showed that the posted speed limit has a significant impact on free-flow speed.

However, if field data are not available, then the free-flow speed can also be estimated indirectly. The findings from a study conducted on rural and suburban multilane highways in Taiwan concluded that the three most important variables that govern the estimation of the space mean free-flow speed are vehicle type, speed limit, and segment length, while lane location, lane width, and the number of median openings or non-signalized intersections per $\mathrm{km}$ do not have any significant impact on the space mean speed [3]. Moreover, according to Razzaq [10], the most critical variables in predicting free flow speed for multilane highways in Najaf city, Iraq, are vehicle type, space mean speed, and the functional classification of the highway. Nevertheless, for two-lane highways, Figueroa and Tarko [11] found that the mean speed reduced slightly as the number of access points increased. This suggests that the median type has a significant impact on operating speed. Further, in the study conducted by Gong and Stamatiadis [12], higher operating speeds were observed on divided four-lane highways than on four-lane undivided highways. Errampalli et al. [13] also stated that the free-flow speed of heavy vehicles and passenger cars was higher in six-lane than in four-lane roads. 
Moreover, Nicholas and Lester [14] mentioned that vehicle speeds tend to be restricted when the lane width is less than $3.6 \mathrm{~m}$ (12 ft.) because, when the lane widths become narrower, the vehicles need to travel closer together, and the speed of vehicles will be reduced. Similar to the effect of lane

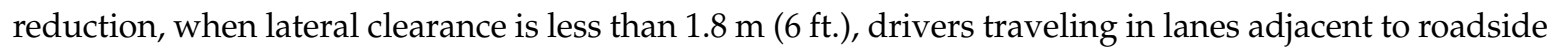
objects will tend to move away from those objects and reduce the speed of their vehicles. Conversely, the effect of lateral clearance on the left shoulder is more significant compared to the clearance from the median. In addition, according to a study conducted by Melo et al. [15] on two-lane highways, cross-sections have an impact on the free-flow speed based on the significance of lane width and shoulder width in their multivariate analysis. Chathoth and Asaithambi [16] also observed that the free-flow speed is directly proportional to the carriageway width, lateral clearance, and link length but indirectly proportional to the number of side roads. Rao and Rao [17] also stated that the number of vehicles, friction points, access points, number of intersections, and number of flyovers make a major contribution to the free-flow speed in urban arterial roads in Delhi.

However, free-flow speed studies under heterogeneous traffic conditions for inter urban multilane highways are very limited, and only a few similar studies conducted on urban roads have been conducted. In a study conducted in Chennai, India, Balakrishnan and Sivanandan [18] found that the free-flow speed on urban roads varies for different vehicle classes. The authors also identified that the average free-flow speed of cars is the highest at $61 \mathrm{~km} / \mathrm{h}$, and the lowest is for three-wheelers at only $40 \mathrm{~km} / \mathrm{h}$. In another study conducted in 2017, the authors compared the free-flow speed predicted using class-wise models and that predicted using basic models. Six separate class-wise models for every class of vehicle were developed and analyzed to determine the effect of vehicle composition on free-flow speed. The authors found that the free-flow speed developed using combinations of class-wise models are more efficient than those using basic models and that the class wise-models also showed that the effects of site factors on free-flow speed were significantly different between vehicle classes, with trucks the least affected by site factors [19]. However, in a separate study conducted by Thomas et al. [20] in India, free-flow speed and acceleration rate were found to be different between vehicle classes and the number of lanes. Two- and three-wheelers, which have the lowest free-flow speeds, often delay the movement of vehicles with higher free-flow speeds and thus increase the overtaking activities. Additionally, the frequent lane changing behavior of smaller vehicles also creates interference due to improper lane discipline. Thus, the size of a vehicle plays a significant role in the variation of speed, especially in a mixed traffic flow. Additionally, Sekhar et al. [21] found that the degree of sensitivity of free-flow speed is more prevalent for smaller cars and that pavement characteristics have a significant impact on the free-flow speed of vehicles at two-lane inter urban highways in India. Ye et al. [22] also concluded that the average free-flow speed computed for cars was higher than that for trucks on arterial roads in Indiana and that the daytime average speed was higher than the nighttime average speed for both cars and trucks.

As such, it is reasonable to conclude that the speed differences between vehicle groups are an important aspect for heterogeneous traffic and that individual free-flow speed is influenced significantly by the class of vehicle it belongs to. The significant difference in free-flow speed across vehicle groups suggests the need for further investigations, especially for inter urban road facilities, which are yet to be fully explored. Thus, this study aims to compare the free-flow speeds measured for different groups of vehicles and subsequently strives to develop a free-flow speed model for inter urban four-lane highways under heterogeneous traffic. The results of this study will improve our understanding of free-flow speeds under mixed traffic conditions and ultimately enhance the design of multilane highways for sustainable development.

\section{Study Methodology}

The analysis procedures for multilane highways are based on the relationship between traffic flow and the speed of vehicles under ideal traffic conditions. The field study for multilane highways was carried out during different hours of the day, and video recording was used to record traffic movement 
over a period of five to six hours, between 7:00 a.m. to 6:30 p.m. under stable flow conditions. For geometric data, the number of lanes, lane width, shoulder width, median clearance, and number of access points along the roadway were recorded manually. During the observations, the lane width and shoulder width were measured using walking measurements. These measurements were collected at least three times (downstream, midpoint, and upstream) and then averaged.

The data collection for multilane highways was done using a video recording approach. At each study location, a CCTV attached to a pole was set up either at the road shoulder or on a bridge if available, to record both directions of the traffic flow of a multilane highway. If an overhead bridge was not available, then a $10 \mathrm{~m}$ pole was used to setup the equipment at the road shoulders. The pole used in this study was specifically fabricated to capture the movement of each vehicle with high accuracy and clear vision. The head of this pole was designed with flexibility in mind to allow adjustments of the angle of the head pole so that the camera could capture the best view to identify the vehicle size and vehicle movement for both lanes in each direction. Figure 1 shows a typical set-up of such equipment on multilane highways in Malaysia.
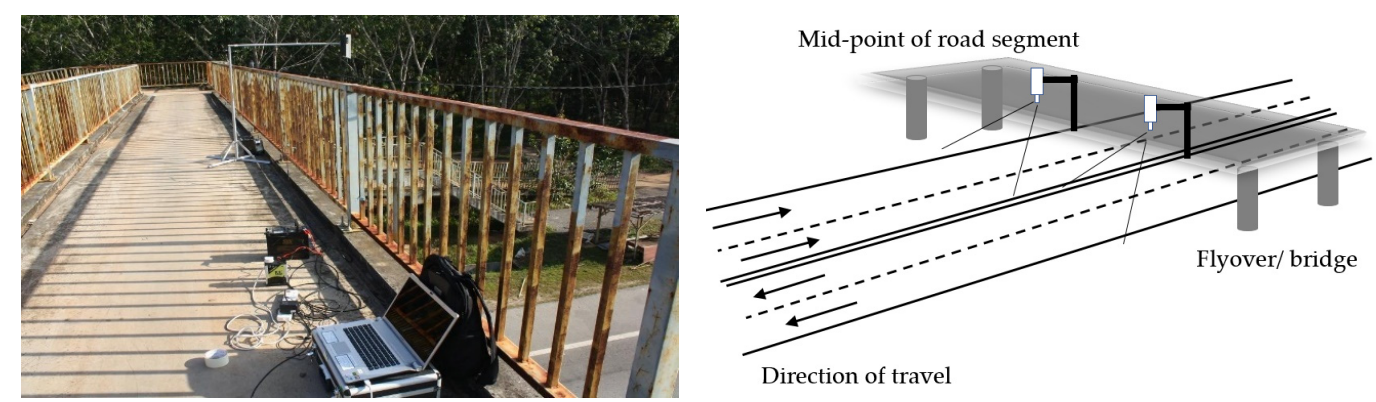

(a)
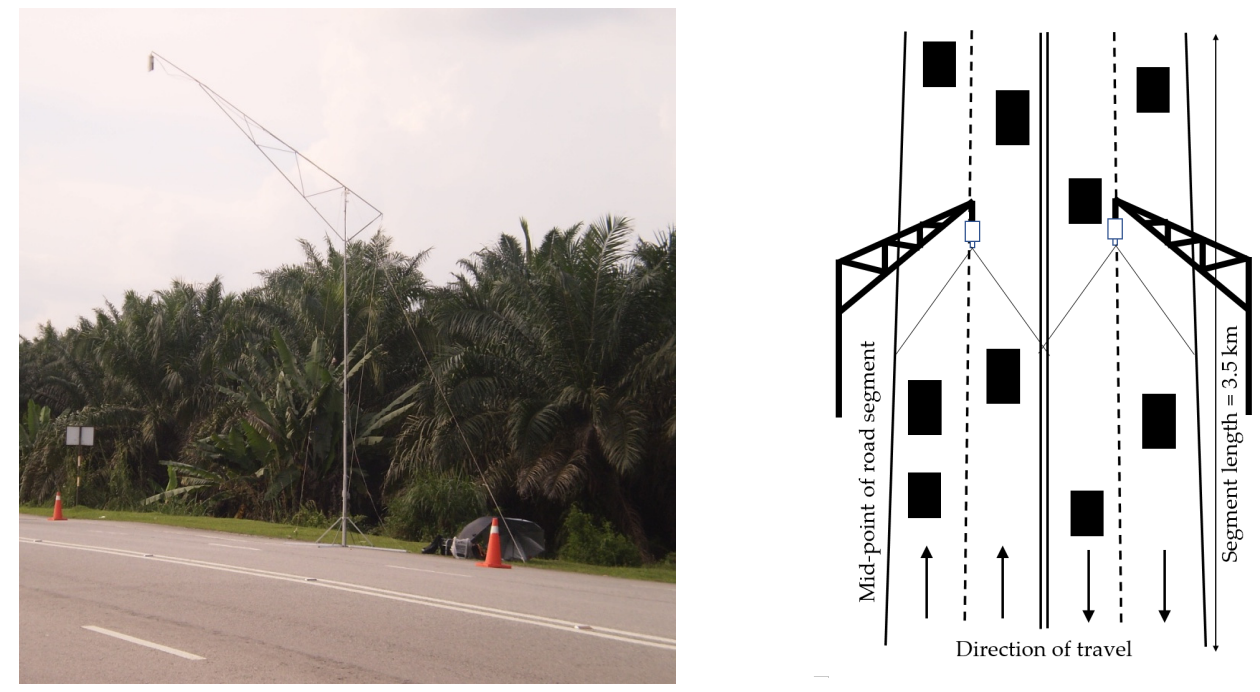

(b)

Figure 1. Equipment set-up on (a) overhead bridge; (b) road shoulder.

Subsequently, the data from the video recorded using CCTV were extracted using image processing software to obtain the desired traffic parameters, such as volume based on the vehicle's classification, speed, and headway. A screen capture of the software interface is shown in Figure 2. As shown in Figure 2, a rectangle shape or region of interest (ROI) is drawn for vehicle detection, and the traffic parameters are displayed when the vehicle crosses the ROI box.

The time mean free-flow speed was calculated by using the mean speed of the vehicles in Class 1 , Class 2, Class 3, Class 4, and Class 5 as follows: 
- Class 1-Cars/small vans/ utilities;

- Class 2-Trucks (with 2 axles)/ large vans;

- Class 3-Large trucks/ trailers/ heavy vehicles with 3 axles or more;

- Class 4-Buses;

- Class 5-Motorcycles.

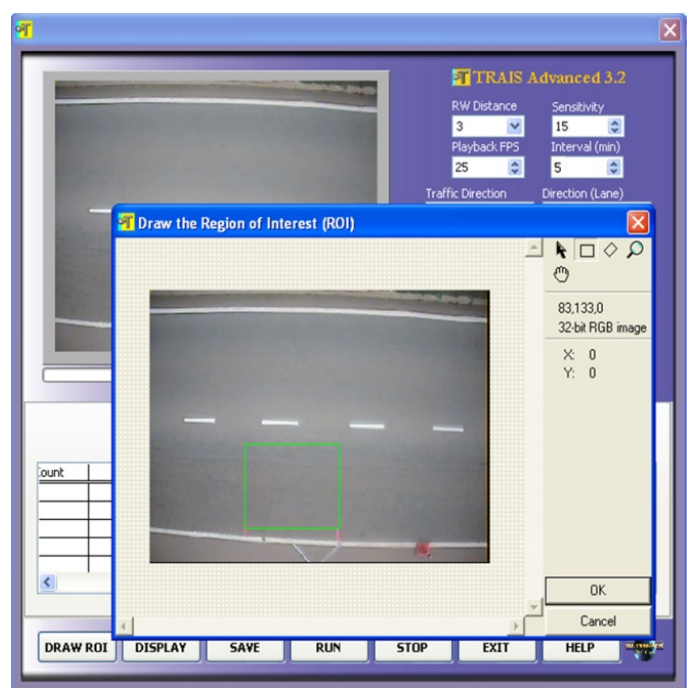

(a)

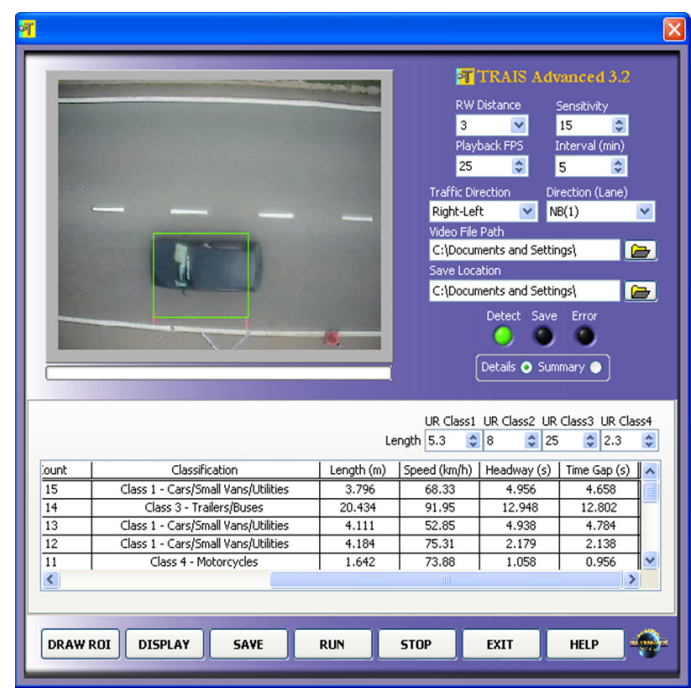

(b)

Figure 2. Interfaces of the image processing software (a) region of interest (ROI) box; (b) vehicle detection.

The speed data were then segregated according to headways of more than $8 \mathrm{~s}$ and then averaged and converted to the space-mean speed to obtain the space-mean free-flow speed using the equation developed by Leong and Awang [23] for the Malaysian Highway Capacity Manual [24] shown in Equation (1).

$$
\bar{v}_{s}=1.021 \bar{v}_{t}-2.528
$$

where

$\bar{v}_{t}=$ Time mean speed;

$\bar{v}_{S}=$ Space-mean speed .

Comparative analyses were then conducted to assess the free-flow speeds computed based on the vehicle classifications. Subsequently, multiple linear regression analyses were conducted to develop the free-flow speed estimation models and performance indicators used to assess and select the best fitted model.

\section{Data Collection}

Data were collected at 16 sites with 64 lanes of four-lane divided and undivided highways with a level gradient in Selangor, Kedah, Pahang, Terengganu, Perlis, and Perak. All the selected roadway segments featured flat terrain and were straight, with no steep hills, intersections, or traffic signals. All sites recorded traffic flow less than $1400 \mathrm{pc} / \mathrm{h} / \mathrm{ln}$ with variations between $83 \mathrm{pc} / \mathrm{h} / \mathrm{ln}$ to $1150 \mathrm{pc} / \mathrm{h} / \mathrm{ln}$. However, due to study limitations and a lack of roadway segments that meet the requirements and conditions for selection, the number of sites suitable for data collection was significantly restricted. The general criteria used to select these sites are summarized in Table 1.

For each segment under study, data were collected for both the inner and outer lane. The inner lane is the lane adjacent to the median of the road and is also known as the fast lane, while the outer lane is the lane adjacent to the shoulder, which is known as the slow lane. The other characteristics 
of the sites, such as lane width, lateral clearance (paved shoulder and median clearance), and access point density were also recorded. Based on the measurements recorded at the sites, the mean lane width was $3.64 \mathrm{~m}$, with a minimum and maximum lane width of $3.34 \mathrm{~m}$ and $3.80 \mathrm{~m}$, respectively. The recorded shoulder widths were between $0.43 \mathrm{~m}$ to $4.02 \mathrm{~m}$ with an average width of $2.08 \mathrm{~m}$; for median clearance, the average width was $0.9 \mathrm{~m}$ with a minimum width of $0.40 \mathrm{~m}$ and a maximum width of $2.50 \mathrm{~m}$. Additionally, the majority of the sites were located in rural areas, and the number of access points collected within the segment was low which (between 1 to 8 access points), while the sites in suburban areas featured a high number of access points-in the range of 5 to 24 access points.

The prevailing geometric conditions were then tested against the base conditions, which were a lane width of $3.65 \mathrm{~m}$, a lateral clearance of $1.8 \mathrm{~m}$, divided highways, no impediments to traffic due to traffic control or turning vehicles, and a level terrain.

Table 1. General criteria for site selection.

\begin{tabular}{cc}
\hline Control & Criteria \\
\hline Area type & Rural and suburban \\
Number of lanes & Four lanes \\
Type of road & Divided and undivided \\
Facility type & Uninterrupted flow \\
Terrain type & Flat/level \\
Segment length & Minimum $3.5 \mathrm{~km}$ \\
Speed limit & No restriction \\
Traffic control & No stop signs or traffic signals \\
\hline
\end{tabular}

Table 2 shows the details of each lane.

Table 2. Site Details Based on Individual Lanes.

\begin{tabular}{|c|c|c|c|c|c|c|c|c|c|c|c|}
\hline $\begin{array}{l}\text { Site } \\
\text { No. }\end{array}$ & $\begin{array}{l}\text { Road } \\
\text { Type }\end{array}$ & $\begin{array}{l}\text { Lane } \\
\text { No. }\end{array}$ & $\begin{array}{l}\text { Lane Width } \\
\text { (m) }\end{array}$ & $\begin{array}{l}\text { Lateral Clearance } \\
(\mathrm{m})\end{array}$ & $\begin{array}{l}\text { Access Point } \\
\text { Density }(/ \mathbf{k m})\end{array}$ & $\begin{array}{l}\text { Site } \\
\text { No. }\end{array}$ & $\begin{array}{l}\text { Road } \\
\text { Type }\end{array}$ & $\begin{array}{l}\text { Lane } \\
\text { No. }\end{array}$ & $\begin{array}{l}\text { Lane Width } \\
\text { (m) }\end{array}$ & $\begin{array}{l}\text { Lateral Clearance } \\
(\mathrm{m})\end{array}$ & $\begin{array}{r}\text { Access Point } \\
\text { Density }(/ \mathbf{k m})\end{array}$ \\
\hline \multirow{4}{*}{1} & $\mathrm{UD}^{1}$ & 1 & 3.60 & 0.63 & \multirow{2}{*}{2.68} & \multirow{4}{*}{9} & \multirow[t]{4}{*}{$\mathrm{D}$} & 33 & 3.64 & 1.94 & \multirow{2}{*}{0.86} \\
\hline & & 2 & 3.60 & 0.00 & & & & 34 & 3.62 & 0.50 & \\
\hline & & 3 & 3.67 & 0.43 & & & & 35 & 3.74 & 1.86 & \multirow{2}{*}{0.86} \\
\hline & & 4 & 3.63 & 0.00 & 1.71 & & & 36 & 3.62 & 0.50 & \\
\hline \multirow{4}{*}{2} & $\mathrm{D}^{2}$ & 5 & 3.70 & 2.47 & \multirow{2}{*}{1.43} & \multirow{4}{*}{10} & \multirow[t]{4}{*}{$\mathrm{D}$} & 37 & 3.72 & 1.84 & \multirow[b]{2}{*}{1.71} \\
\hline & & 6 & 3.70 & 1.00 & & & & 38 & 3.68 & 0.62 & \\
\hline & & 7 & 3.63 & 2.70 & \multirow[b]{2}{*}{0.86} & & & 39 & 3.66 & 2.26 & \multirow{2}{*}{0.86} \\
\hline & & 8 & 3.63 & 1.00 & & & & 40 & 3.68 & 0.72 & \\
\hline \multirow{4}{*}{3} & $\mathrm{D}$ & 9 & 3.70 & 2.63 & \multirow{2}{*}{1.14} & \multirow{4}{*}{11} & \multirow[t]{4}{*}{$\mathrm{D}$} & 41 & 3.70 & 2.02 & \multirow{2}{*}{0.86} \\
\hline & & 10 & 3.70 & 2.00 & & & & 42 & 3.58 & 0.50 & \\
\hline & & 11 & 3.67 & 2.57 & & & & 43 & 3.58 & 2.06 & \multirow[b]{2}{*}{1.43} \\
\hline & & 12 & 3.67 & 2.00 & 0.86 & & & 44 & 3.64 & 2.50 & \\
\hline \multirow{4}{*}{4} & $\mathrm{D}$ & 13 & 3.63 & 2.37 & \multirow[b]{2}{*}{1.71} & \multirow{4}{*}{12} & \multirow[t]{4}{*}{$\mathrm{D}$} & 45 & 3.56 & 1.96 & \multirow{2}{*}{2.29} \\
\hline & & 14 & 3.67 & 0.50 & & & & 46 & 3.52 & 0.54 & \\
\hline & & 15 & 3.73 & 3.27 & & & & 47 & 3.62 & 2.78 & \multirow[b]{2}{*}{2.00} \\
\hline & & 16 & 3.60 & 0.50 & 1.14 & & & 48 & 3.58 & 0.56 & \\
\hline \multirow{4}{*}{5} & $\mathrm{D}$ & 17 & 3.73 & 2.07 & \multirow{2}{*}{1.14} & & $\mathrm{D}$ & 49 & 3.62 & 2.12 & \\
\hline & & 18 & 3.67 & 1.25 & & & & 50 & 3.58 & 0.58 & 0.29 \\
\hline & & 19 & 3.80 & 1.87 & & 13 & & 51 & 3.64 & 2.06 & \\
\hline & & 20 & 3.73 & 1.15 & 1.14 & & & 52 & 3.64 & 0.84 & 0.29 \\
\hline & UD & 21 & 3.66 & 0.50 & & & $\mathrm{D}$ & 53 & 3.64 & 2.00 & \\
\hline & & 22 & 3.60 & 0.00 & 1.43 & & & 54 & 3.64 & 0.40 & 3.14 \\
\hline 6 & & 23 & 3.54 & 0.44 & & 14 & & 55 & 3.70 & 1.60 & \\
\hline & & 24 & 3.58 & 0.00 & 1.43 & & & 56 & 3.70 & 0.52 & 1.43 \\
\hline & $\mathrm{D}$ & 25 & 3.56 & 2.64 & & & $\mathrm{D}$ & 57 & 3.74 & 4.02 & \\
\hline & & 26 & 3.56 & 1.76 & 1.14 & & & 58 & 3.64 & 0.48 & 7.43 \\
\hline 7 & & 27 & 3.62 & 2.42 & & 15 & & 59 & 3.72 & 3.38 & \\
\hline & & 28 & 3.54 & 1.54 & 1.14 & & & 60 & 3.74 & 0.50 & 11.43 \\
\hline & UD & 29 & 3.70 & 2.12 & & & $\mathrm{D}$ & 61 & 3.60 & 1.96 & \\
\hline & & 30 & 3.34 & 0.00 & 1.43 & & & 62 & 3.62 & 0.46 & 2.29 \\
\hline 8 & & 31 & 3.70 & 1.66 & & 16 & & 63 & 3.62 & 1.94 & \\
\hline & & 32 & 3.48 & 0.00 & 1.43 & & & 64 & 3.62 & 0.44 & 1.71 \\
\hline
\end{tabular}

${ }^{1} \mathrm{U}=$ Divided,${ }^{2} \mathrm{UD}=$ Undivided. 


\section{Results and Discussions}

\subsection{Free-Flow Speeds Based on Vehicle Classes}

Initially, assessments of the mean free-flow speed according to vehicle classification were conducted. In this study, free-flow speed was estimated based on the average the speed of the vehicle with headway to the nearest vehicle in front of more than $8 \mathrm{~s}$ and no recent or immediate meeting with a vehicle in the opposing direction. Thus, the data that do not represent free flow conditions were eliminated from the analysis, and free-flow speed data for a total of 41,154 vehicles were collected; the highest number of vehicles was recorded in Class 1 at 28,795 vehicles (or 70.0\%), followed by Class 2 with 4943 vehicles (12.0\%), Class 5 with 4265 vehicles (10.4\%), Class 3 with 2835 vehicles (6.9\%), and, lastly, Class 4 with only 316 vehicles $(0.8 \%)$.

The descriptive statistics of the average free-flow speeds observed for vehicles in Classes 1, 2, 3, 4, and 5 based on individual lanes are as shown in Table 3. Table 2 shows that the mean free-flow speed for vehicles in Class 1 yields the highest value $(82.5 \mathrm{~km} / \mathrm{h})$, while the lowest mean free-flow speed of $71.8 \mathrm{~km} / \mathrm{h}$ was observed for vehicles in Class 5 .

Table 3. Descriptive statistics for free-flow speed based on vehicle classifications.

\begin{tabular}{|c|c|c|c|c|c|c|c|c|}
\hline \multirow{2}{*}{ Class } & \multirow{2}{*}{$\mathbf{N}$} & \multirow{2}{*}{ Mean } & \multirow{2}{*}{ Std. Deviation } & \multirow{2}{*}{ Std. Error } & \multicolumn{2}{|c|}{ 95\% Confidence Interval for Mean } & \multirow{2}{*}{ Min. } & \multirow{2}{*}{ Max. } \\
\hline & & & & & Lower Bound & Upper Bound & & \\
\hline 1 & 28,795 & 82.5002 & 9.7466 & 1.2183 & 80.0651 & 84.9343 & 61.63 & 102.34 \\
\hline 2 & 4943 & 78.6419 & 9.0680 & 1.1335 & 76.3771 & 80.9073 & 62.95 & 98.65 \\
\hline 3 & 2835 & 78.1560 & 8.8196 & 1.1025 & 75.9524 & 80.3585 & 62.93 & 104.85 \\
\hline 4 & 316 & 79.6992 & 11.2322 & 1.4877 & 76.7181 & 82.6787 & 61.25 & 105.18 \\
\hline 5 & 4265 & 71.7745 & 11.6602 & 1.4808 & 68.8132 & 74.7355 & 51.54 & 95.74 \\
\hline
\end{tabular}

However, in order to compare the mean free-flow speed of each vehicle class, a one-way ANOVA test was conducted. The results of the one-way ANOVA are shown in Table 2. Based on the results in Table 4 , the $p$-value is less than 0.05 , which means that the null hypothesis was rejected. Therefore, it can be concluded that the mean free-flow speeds for different classes of vehicles were significantly different. Subsequently, post hoc range tests and pairwise multiple comparisons were conducted to determine which means differed from each other. Range tests were used to identify the homogeneous subsets of means that are not different from each other, while pairwise multiple comparisons tested the difference between each pair of means.

Table 4. A one-way ANOVA for free-flow speed based on vehicle classifications.

\begin{tabular}{cccccc}
\hline & Sum of Squares & df & Mean Square & F & $p$-Value \\
\hline Between Groups & 3883.231 & 4 & 970.808 & 9.453 & $<0.001$ \\
Within Groups & $31,424.143$ & 306 & 102.693 & & \\
Total & $35,307.375$ & 310 & & & \\
\hline
\end{tabular}

However, in order to select an appropriate post hoc test, a Levene test for equality of variances was used to test whether the two samples had statistically equivalent variances. Table 5 shows the results. Based on the results from the Levene test of homogeneity of variance, the Levene statistic is 3.060 with a $p$-value of 0.017 . Thus, at a $95 \%$ confidence interval, the null hypothesis of equal variances across the five classes of vehicles was rejected.

Table 5. Levene's test of homogeneity of variance for free-flow speed based on vehicle classifications.

\begin{tabular}{cccc}
\hline Levene Statistic & df1 & df2 & $\boldsymbol{p}$-Value \\
\hline 3.060 & 4 & 306 & 0.017 \\
\hline
\end{tabular}


Upon determining that the means of free-flow speed were significantly different for different classes of vehicles with unequal variances, post hoc multiple comparison procedures were conducted to determine exactly which groups were different from the others, either because the means of free-flow speed were different for all five classes of vehicles or because only one class differed from the rest. The results from the post hoc test are shown in Table 6 . Based on the results, at a $95 \%$ confidence interval, the mean free-flow speeds for vehicles in Class 1, 2, 3, and 4 were not significantly different from each other, but they were significantly different from the mean free-flow speed of the vehicles in Class 5 .

Table 6. Post hoc multiple comparisons for free-flow speed based on vehicle classifications.

\begin{tabular}{|c|c|c|c|c|c|c|}
\hline \multirow{2}{*}{ (I) Class } & \multirow{2}{*}{ (J) Class } & \multirow{2}{*}{ Mean Difference (I-J) } & \multirow{2}{*}{ Std. Error } & \multirow{2}{*}{ Sig. } & \multicolumn{2}{|c|}{ 95\% Confidence Interval } \\
\hline & & & & & Lower Bound & Upper Bound \\
\hline \multirow[t]{4}{*}{1} & 2.00 & 3.85750 & 1.66407 & 0.197 & -0.8805 & 8.5955 \\
\hline & 3.00 & 4.34422 & 1.64308 & 0.088 & -0.3344 & 9.0228 \\
\hline & 4.00 & 2.80127 & 1.92293 & 0.789 & -2.6851 & 8.2876 \\
\hline & 5.00 & 10.72533 * & 1.91760 & $<0.001$ & 5.2604 & 16.1903 \\
\hline \multirow[t]{4}{*}{2} & 1.00 & -3.85750 & 1.66407 & 0.197 & -8.5955 & 0.8805 \\
\hline & 3.00 & 0.48672 & 1.58120 & 1.000 & -4.0150 & 4.9884 \\
\hline & 4.00 & -1.05623 & 1.87034 & 1.000 & -6.3963 & 4.2839 \\
\hline & 5.00 & $6.86783 *$ & 1.86486 & 0.004 & 1.5502 & 12.1855 \\
\hline \multirow[t]{4}{*}{3} & 1.00 & -4.34422 & 1.64308 & 0.088 & -9.0228 & 0.3344 \\
\hline & 2.00 & -0.48672 & 1.58120 & 1.000 & -4.9884 & 4.0150 \\
\hline & 4.00 & -1.54295 & 1.85169 & 0.994 & -6.8314 & 3.7455 \\
\hline & 5.00 & $6.38111 *$ & 1.84616 & 0.008 & 1.1155 & 11.6468 \\
\hline \multirow[t]{4}{*}{4} & 1.00 & -2.80127 & 1.92293 & 0.789 & -8.2876 & 2.6851 \\
\hline & 2.00 & 1.05623 & 1.87034 & 1.000 & -4.2839 & 6.3963 \\
\hline & 3.00 & 1.54295 & 1.85169 & 0.994 & -3.7455 & 6.8314 \\
\hline & 5.00 & $7.92407 *$ & 2.09911 & 0.003 & 1.9400 & 13.9082 \\
\hline \multirow[t]{4}{*}{5} & 1.00 & $-10.72533 *$ & 1.91760 & $<0.001$ & -16.1903 & -5.2604 \\
\hline & 2.00 & $-6.86783 *$ & 1.86486 & 0.004 & -12.1855 & -1.5502 \\
\hline & 3.00 & $-6.38111^{*}$ & 1.84616 & 0.008 & -11.6468 & -1.1155 \\
\hline & 4.00 & $-7.92407^{*}$ & 2.09911 & 0.003 & -13.9082 & -1.9400 \\
\hline
\end{tabular}

* Pairs of means that were significantly different at 0.05 level.

\subsection{Free-Flow Speed Models Using Multiple Linear Regression}

In this study, only three groups of vehicle classifications were used to develop free-flow speed models for several reasons. Firstly, as traffic in Malaysia consist of five vehicle classes, there is a need to ascertain whether the free-flow speed of all vehicle classes should be used in the formulation of a free-flow speed equation. Therefore, the free-flow speeds of all vehicles were initially grouped in Group 1, which is the base group. Subsequently, because the mean free-flow speed of motorcycles (Class 5) is the lowest at only $71.77 \mathrm{~km} / \mathrm{h}$, motorcycles deviate the most from the free-flow speed of other vehicle classifications. Hence, there is a need to investigate the impact of this vehicle class on the overall free-flow speed by comparing the results from Group 2 with the results from Group 1. Lastly, because the average free-flow speed of light vehicles or cars in Class 1 is only slightly higher than the mean free-flow speed of heavy vehicles in Class 2, Class 3, and Class 4, there is a need to investigate the impact of heavy vehicles on the overall free-flow speed, which can be done by comparing the results from Group 2 with the results from Group 3.

Initially, a descriptive statistical analysis was conducted to investigate the trends of the grouped free-flow speeds, and the results are shown in Table 7 . The calculated mean values shown in Table 7 indicate that the mean free-flow speed of all vehicles yields the lowest value of $80.8 \mathrm{~km} / \mathrm{h}$, while the mean free-flow speed of cars is the highest at $82.5 \mathrm{~km} / \mathrm{h}$. Additionally, for free-flow speeds, Group 1 yields the highest standard deviation value, while the free-flow speeds for Group 3 yield the lowest standard deviation value. This is because, in Group 1, the free-flow speeds of motorcycles are included in the analysis, and, due to their lower free-flow speed values, grouping them together with other 
higher free-flow speed values causes the data points to become more spread out over a wider range of values. On the other hand, due to the proximity of the free-flow speed values obtained for the vehicles in Classes 1 to 4, when grouped together (as in Groups 2 and 3), they yield smaller standard deviation values. However, due to different vehicle classes in Group 2 and the different operating conditions of cars in Group 3, there is still variation in the observed free-flow speeds. Considering the differences between the minimum and maximum free-flow speeds observed for the vehicles in Groups 2 and 3 (around $40 \mathrm{~km} / \mathrm{h}$ ), the standard deviation of around $9.7 \mathrm{~km} / \mathrm{h}$ is still acceptable as the standard deviation value, which demonstrates how spread out the data are. Further analyses to determine the spread of the data points in Groups 1, 2, and 3 indicated that, respectively, $66 \%, 98 \%$, and $100 \%$ of the data points in Group 1 are within \pm 1SD, \pm 2 SD, and \pm 3SD of the mean. Similarly, $66 \%, 95 \%$, and $100 \%$ of the data points in Group 2, respectively, fall within \pm 1 SD, \pm 2 SD and \pm 3 SD of the mean. Lastly, $64 \%, 97 \%$, and $100 \%$ of the data points in Group 3 are, respectively, within $\pm 1 S D$, $\pm 2 \mathrm{SD}$, and $\pm 3 \mathrm{SD}$ of the mean.

Table 7. Descriptive statistics for free-flow speed based on vehicle groups.

\begin{tabular}{ccccccccc}
\hline \multirow{2}{*}{ Class } & \multirow{2}{*}{$\mathbf{N}$} & \multirow{2}{*}{ Mean } & \multirow{2}{*}{ Std. Deviation } & \multirow{2}{*}{ Std. Error } & \multicolumn{2}{c}{$\mathbf{9 5 \% \text { Confidence Interval for Mean }}$} & \multirow{2}{*}{ Min. } & \multirow{2}{*}{ Max. } \\
\cline { 6 - 7 } & & & & Lower Bound & Upper Bound & & \\
\hline 1 & 64 & 80.8339 & 10.50551 & 1.31319 & 78.2097 & 83.4581 & 59.97 & 102.17 \\
2 & 64 & 81.8517 & 9.76208 & 1.22026 & 79.4132 & 84.2902 & 61.92 & 102.17 \\
3 & 64 & 82.4997 & 9.74658 & 1.21832 & 80.0651 & 84.9343 & 61.63 & 102.34 \\
\hline
\end{tabular}

Subsequently, multiple linear regression analyses were conducted to develop the equation to estimate free-flow speed. A similar approach was adopted by Balakrishnan and Sivanandan [18] to develop free-flow speed models for urban roads under heterogeneous traffic conditions in India. This approach was also used in the Highway Capacity Manual [1] to estimate free-flow speed based on the physical characteristics of any multilane segment in the United States of America. The independent variable used for each model is as follows:

- Model 1-free-flow speed of all vehicles (Class 1, 2, 3, 4, and 5);

- Model 2-free-flow speed of vehicles excluding motorcycles (Class 1, 2, 3, and 4);

- Model 3-free-flow speed of cars only (Class 1).

In order to develop free-flow speed models under prevailing conditions, the factors affecting free-flow speed, such as lane width, shoulder width, median clearance, access point density, and lane position, were investigated and are included in the model. In this study, lateral clearance is divided into two types: shoulder width and median clearance. Shoulder width refers to the width of the paved shoulder, which is measured from the left edge of the travel lane, while median clearance is measured from the right edge of the travel lane to the median. For divided highways, shoulder width is considered to be the lateral clearance for the outer lane, and median clearance is considered to be lateral clearance for the inner lane. However, for undivided highways, only shoulder width is considered as the lateral clearance for the outer lane, while the lateral clearance for the inner lane is zero. Additionally, a dummy variable indicating lane position was also included in the regression model. The ideal conditions for multilane highways based on the Malaysian road geometry design guidelines [1] and Highway Capacity Manual [2] are as follows:

- Lane width greater than or equal to $3.65 \mathrm{~m}$;

- Lateral clearance wider than or equal to $1.8 \mathrm{~m}$;

- Divided highways;

- No impediment to traffic due to traffic control or turning vehicles;

- Level terrain.

Initially, the obtained values of free-flow speed were investigated based on lane position. Figure 3 shows that all the values of free-flow speed obtained for the inner lane or fast lane were higher than 
those obtained for outer lane. As such, a dummy variable indicating lane position was included in all three regression models. The general equation adopted in this study to estimate the free-flow speed of multilane highways in Malaysia is shown as Equation (2):

$$
F F S=B F F S-f_{L W}-f_{L C}-f_{M}-f_{A}
$$
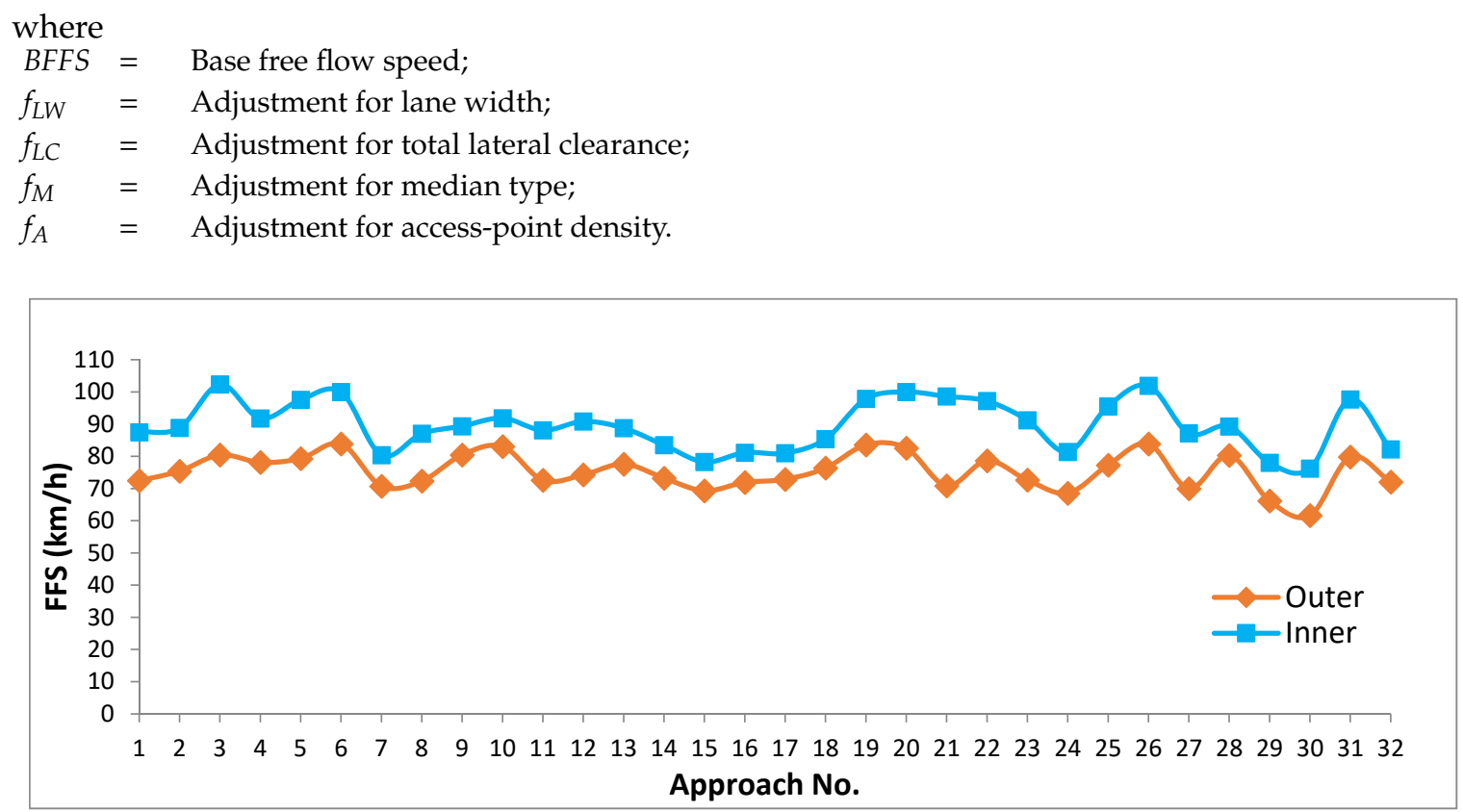

Figure 3. Free-flow speeds calculated based on lane position.

The developed free-flow speed models are as shown in Equations (3)-(5). Table 8 shows a summary of the regression analyses for Models 1,2 , and 3 . In the regression equation, the coefficient of the lane width factor will only determine the rate at which the speed will decrease for every $0.1 \mathrm{~m}$ of lane width less than $3.65 \mathrm{~m}$, with no increment in free-flow speed for lane widths of more than $3.65 \mathrm{~m}$. Similarly, the coefficient of lateral clearance will indicate the rate at which the speed will decrease for every meter of the shoulder width or median clearance less than $1.8 \mathrm{~m}$. For the factor of access point density, the coefficient provided by the regression equation directly estimates the speed reduction penalty for every access point found within $1 \mathrm{~km}$. Lastly, since all surveyed sites have level terrain, the effect of the gradient is not considered in the regression analyses.

$$
\begin{gathered}
\text { Model } 1\left(\mathrm{R}^{2}=0.954\right): \\
F F S=B F F S-43.502(3.65-L W)-4.462(1.8-L C)-3.437(A P D)-22.937(L D) \\
\text { Model } 2\left(\mathrm{R}^{2}=0.949\right): \\
F F S=B F F S-44.262(3.65-L W)-4.308(1.8-L C)-3.431(A P D)-21.058(L D) \\
\text { Model } 3\left(R^{2}=0.946\right): \\
F F S=B F F S-41.878(3.65-L W)-4.142(1.8-L C)-3.426(A P D)-20.329(L D)
\end{gathered}
$$

where

BFFS = Base free flow speed $(100 \mathrm{~km} / \mathrm{h}$ for multilane highways);

$L W=$ Lane width (ideal lane width $=3.65 \mathrm{~m}$ );

$L C=$ Lateral clearance, adjustment of shoulder width for the outer lane, and adjustment of

median clearance for the inner lane (ideal lateral clearance $=1.8 \mathrm{~m}$ );

$A P D=$ Access point density;

$L D=$ Lane dummy ( 0 if inner lane, 1 if outer lane). 
Table 8. A summary of the regression analysis for free-flow speed models.

\begin{tabular}{cccccc}
\hline \multirow{2}{*}{ Model } & Variable & \multicolumn{2}{c}{ Unstandardized Coefficients } & \multirow{t}{*}{$\boldsymbol{t}$-Value } & $\boldsymbol{p}$-Value \\
\cline { 3 - 4 } & & $\mathbf{B}$ & Standard Error & & \\
\hline \multirow{2}{*}{1} & LW & 43.502 & 14.218 & 3.060 & 0.003 \\
& SH & 4.462 & 1.125 & 3.966 & $<0.001$ \\
& APD & 3.437 & 0.520 & 6.606 & $<0.001$ \\
& LD & 22.937 & 1.259 & 18.216 & $<0.001$ \\
2 & LW & 44.262 & 14.110 & 3.137 & 0.003 \\
& SH & 4.303 & 1.117 & 3.854 & $<0.001$ \\
& APD & 3.431 & 0.516 & 6.645 & $<0.001$ \\
& LD & 21.058 & 1.250 & 16.851 & $<0.001$ \\
3 & LW & 41.878 & 14.162 & 2.957 & 0.004 \\
& SH & 4.142 & 1.121 & 3.696 & $<0.001$ \\
& APD & 3.426 & 0.518 & 6.611 & $<0.001$ \\
& LD & 20.329 & 1.254 & 16.208 & $<0.001$ \\
\hline
\end{tabular}

However, regression analysis requires the assumption that the residual (error) is normally distributed with a zero mean and constant variance to obtain the best model. Residual analyses were then conducted to check these assumptions. A normal probability plot can be used to test whether the error terms are normally distributed or otherwise and presents a plot of a variable's cumulative proportions (the proportion of the distribution that is less than the specified value) against the cumulative proportions of a theoretical normal distribution. If the error terms are normally distributed, the points cluster around a $45^{\circ}$ straight line. The normal probability plots generated for Models 1, 2, and 3 using statistical software are shown in Figure 4. Based on the results, the data points are distributed roughly around a $45^{\circ}$ straight line, thus indicating that the normality assumption for each model is satisfied.

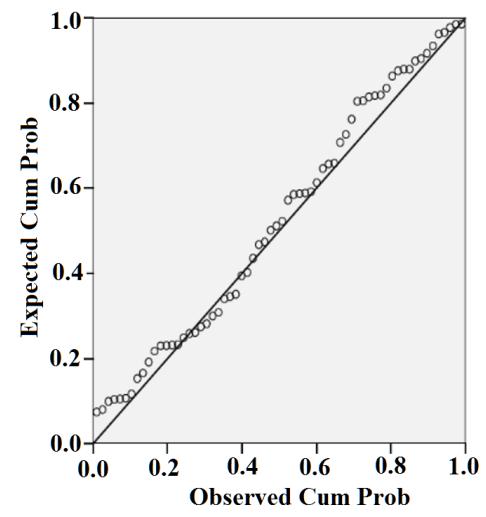

(a)

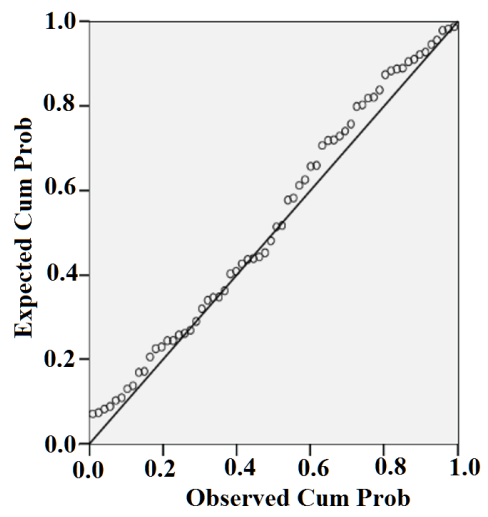

(b)

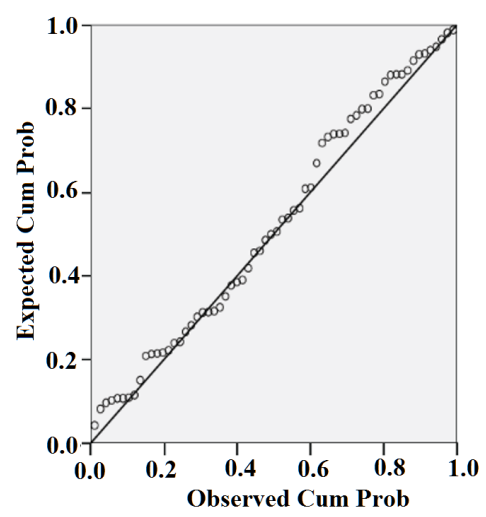

(c)

Figure 4. Normal probability plot generated for free-flow speed models: (a) Model 1; (b) Model 2; (c) Model 3.

Additionally, residuals are plotted against the fitted values determine to determine whether non-constant variance exists. If the points in the residual plot show no pattern, then the variance is constant. Based on the residual plots shown in Figure 5, which were generated using statistics, the data points appear to be randomly scattered around the horizontal axis; thus, the variance is constant. Therefore, the developed regression equations are valid and acceptable.

Subsequently, analyses using performance indicators (PIs) were conducted to select the best free-flow speed model. These analyses involved three error measures (root mean square error (RMSE), normalized absolute error (NAE), and Mean Absolute Percentage Error (MAPE)) and three accuracy measures (index of agreement (IA), prediction accuracy (PA), and coefficient of determination $\left(\mathrm{R}^{2}\right)$ ). To produce a good estimator, the error measures must have values close to zero, as small values of 
RMSE, NAE, and MAPE indicate that the developed models have smaller errors. For the measures of accuracy, the obtained values should be nearer to 1 , as higher values of PA, IA, and $\mathrm{R}^{2}$ suggest that the developed models can predict well.

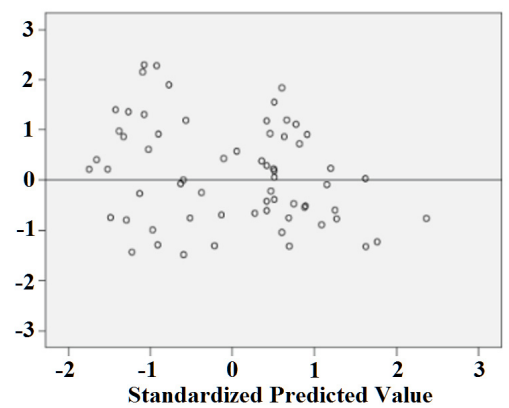

(a)

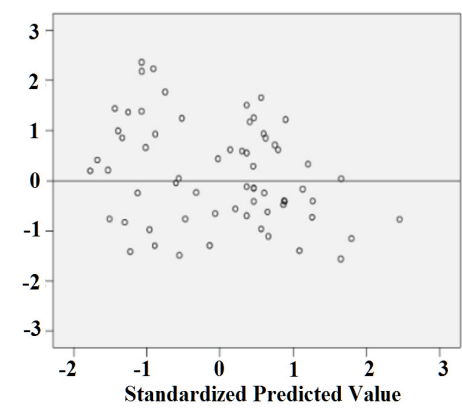

(b)

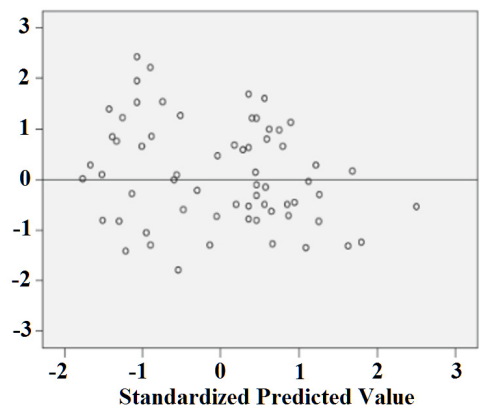

(c)

Figure 5. Residuals plotted against the fitted values for the free-flow speed models: (a) Model 1; (b) Model 2; (c) Model 3.

A score system was then formulated to select the best model. For the error measure, the models are ranked from the highest, with a score of 1 , to the smallest, with a score of 3 . The accuracy measures are ranked from the smallest, with a score of 1 , to the highest, with a score of 3 . The total score for each model is calculated by adding the score obtained in each PI, which can be between a minimum score of 5 (i.e., each PI only obtained a minimum score of 1) and a maximum score of 18 (each PI obtained a maximum score of 3). The results are summarized in Table 9. Based on the results shown in Table 9, Model 2 has the lowest score of 9, which indicates that Model 2 is the least favorable model. Conversely, Model 1 which has the highest score of 15, making it the most favorable model. This suggests that the mean free-flow speed of all vehicles, including heavy vehicles and motorcycles, should be used to measure free-flow speed.

Table 9. Summary of the performance indicator (PI) values for the free-flow speed models.

\begin{tabular}{ccccccccc}
\hline \multicolumn{2}{c}{ Model } & NAE & RMSE & MAPE & IA & PA & $\mathbf{R}^{2}$ & Total Score \\
\hline \multirow{2}{*}{1} & Value & 0.0660 & 6.3816 & $6.76 \%$ & 0.8902 & 0.8307 & 0.954 & \\
& Score & 2 & 2 & 2 & 3 & 3 & 3 & 15 \\
\hline \multirow{2}{*}{2} & Value & 0.0698 & 6.7761 & $7.12 \%$ & 0.8764 & 0.8102 & 0.949 & \\
& Score & 1 & 1 & 1 & 2 & 2 & 2 & 9 \\
\hline \multirow{2}{*}{3} & Value & 0.0626 & 6.2772 & $6.39 \%$ & 0.8754 & 0.8066 & 0.946 & \\
& Score & 3 & 3 & 3 & 1 & 1 & 1 & 12 \\
\hline
\end{tabular}

In order to visualize and compare the estimated free-flow speeds based on Model 1 with the observed free-flow speeds, a bar chart showing the percentages of differences was plotted, and the results are shown in Figure 6. Based on the plot in Figure 6, the highest difference existed between Lane 60 and Lane 15. For Lane 15, Model 1 overestimated the free-flow speed by 22.5\%, while for Lane 60 , Model 1 underestimated the free-flow speed by $-22.4 \%$. However, on average, the percentages of overestimation and underestimation are only $6.1 \%$ and $-7.4 \%$, respectively, with 30 lanes recording an overestimation of free-flow speeds and 34 lanes recording an underestimation of free-flow speeds. Consequently, the few lanes with high percentages of differences might be due to other external factors, such as a high volume of heavy vehicles and motorcycles, as heterogeneous traffic streams usually contain a mix of different vehicles, such as trucks, trailers, passenger cars, buses, and motorcycles. The high percentage of heavy vehicles in this traffic stream will cause a significant decrease in the free-flow speed. Moreover, heavy vehicles tend to impede passenger cars due to their slower speeds, which will create difficulties for passenger cars to overtake them. Most motorcycles travel on the road 
shoulder. However, if the road has a smaller shoulder width, motorcyclists will tend to ride in the same lane, either beside, in front of, or following other vehicles, albeit with a much slower speed. As a motorcycle is much smaller than other vehicles, motorcycles can easily be overtaken, usually without needing to move into an adjacent lane to overtake them. Therefore, if the volume of motorcycles is high, the tendency to overtake them will also be higher, which will affect the free-flow speed of the other vehicles, especially if the motorcycles are traveling beside other vehicles in the same lane. Figure 7 shows the effects of heavy vehicles and motorcycles on the free-flow speed of passenger cars. It can be observed from the trend of the scatterplot that a higher percentage of heavy vehicles and motorcycles causes a reduction in the free-flow speed of passenger cars.

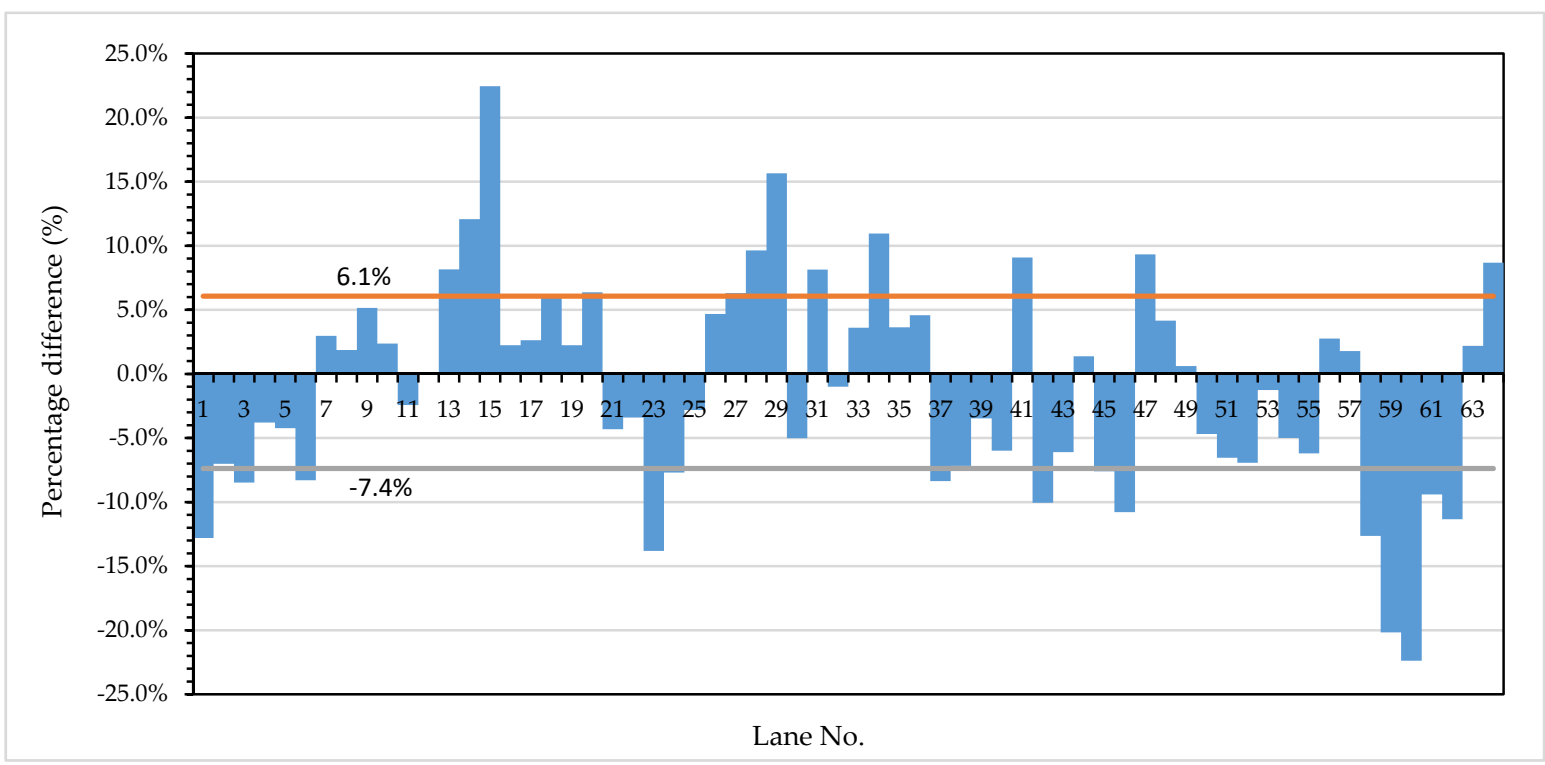

Figure 6. Comparisons of the estimated free-flow speeds with the observed free-flow speeds.

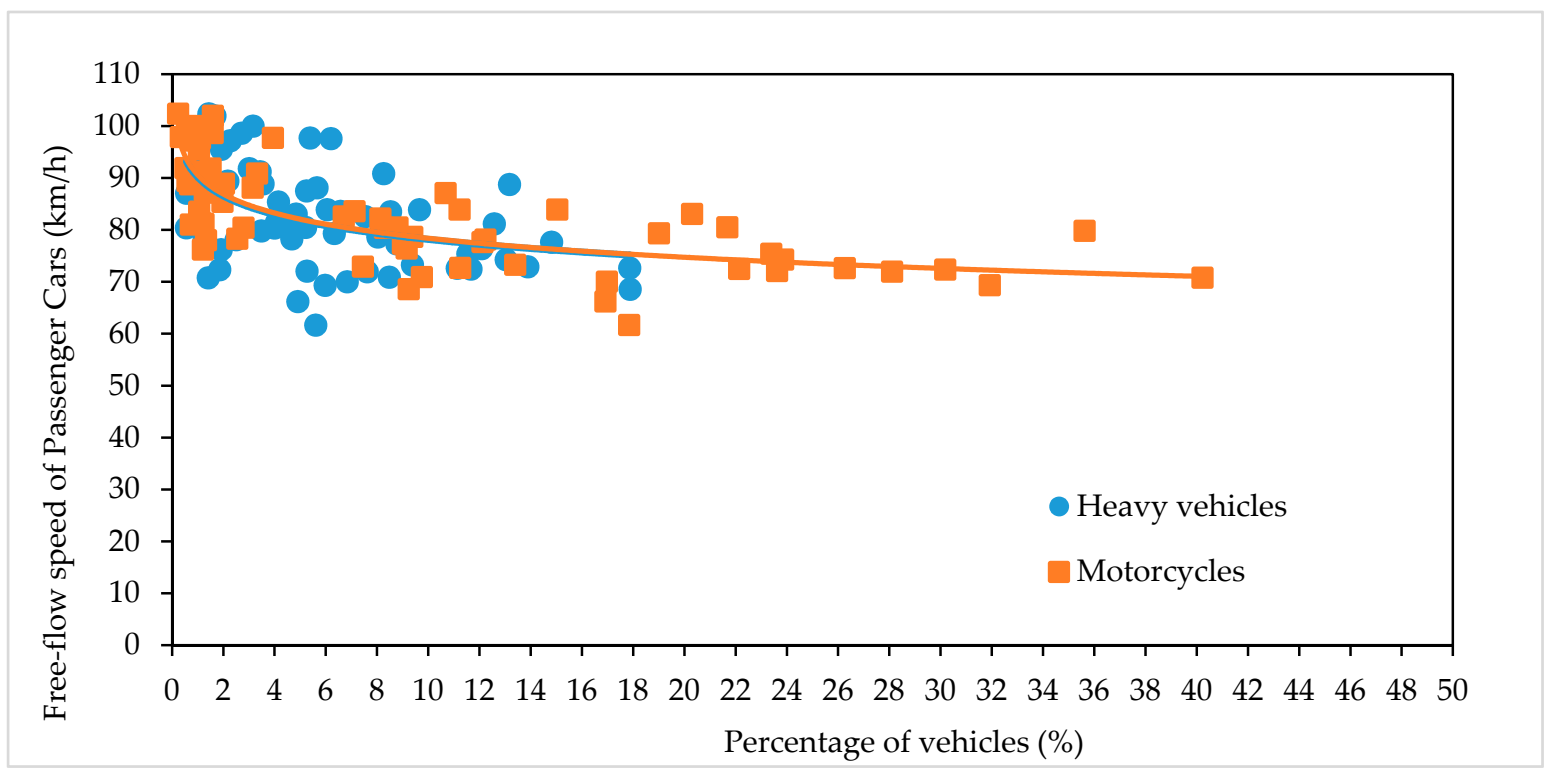

Figure 7. Effects of heavy vehicles and motorcycles on the free-flow speed of passenger cars.

The findings of this study are consistent to some extent with the findings of Balakrishnan and Sivandan [18], who mentioned that, for heterogeneous traffic, a combined class-wise model is more efficient in predicting the overall free-flow speed compared to the base model, which is predominantly focused on passenger cars. However, in this study, the proportions of different vehicle classes were 
not considered in the free-flow speed estimation model as a traffic composition factor, and, together with the peak hour factor, is applied during the calculation of the demand flow rate to determine the level-of-service of multilane highways. Therefore, by adopting the level-of-service criteria given in the Malaysian Highway Capacity Manual [24] (as shown in Table 10), the level-of-service of each lane determined based on the estimated free-flow speeds using Model 1 were compared with the level-of-service determined based on the observed free-flow speeds. The results are shown in Table 11.

Table 10. Level-of-service criteria according to the selected free-flow speed based on the Malaysian Highway Capacity Manual.

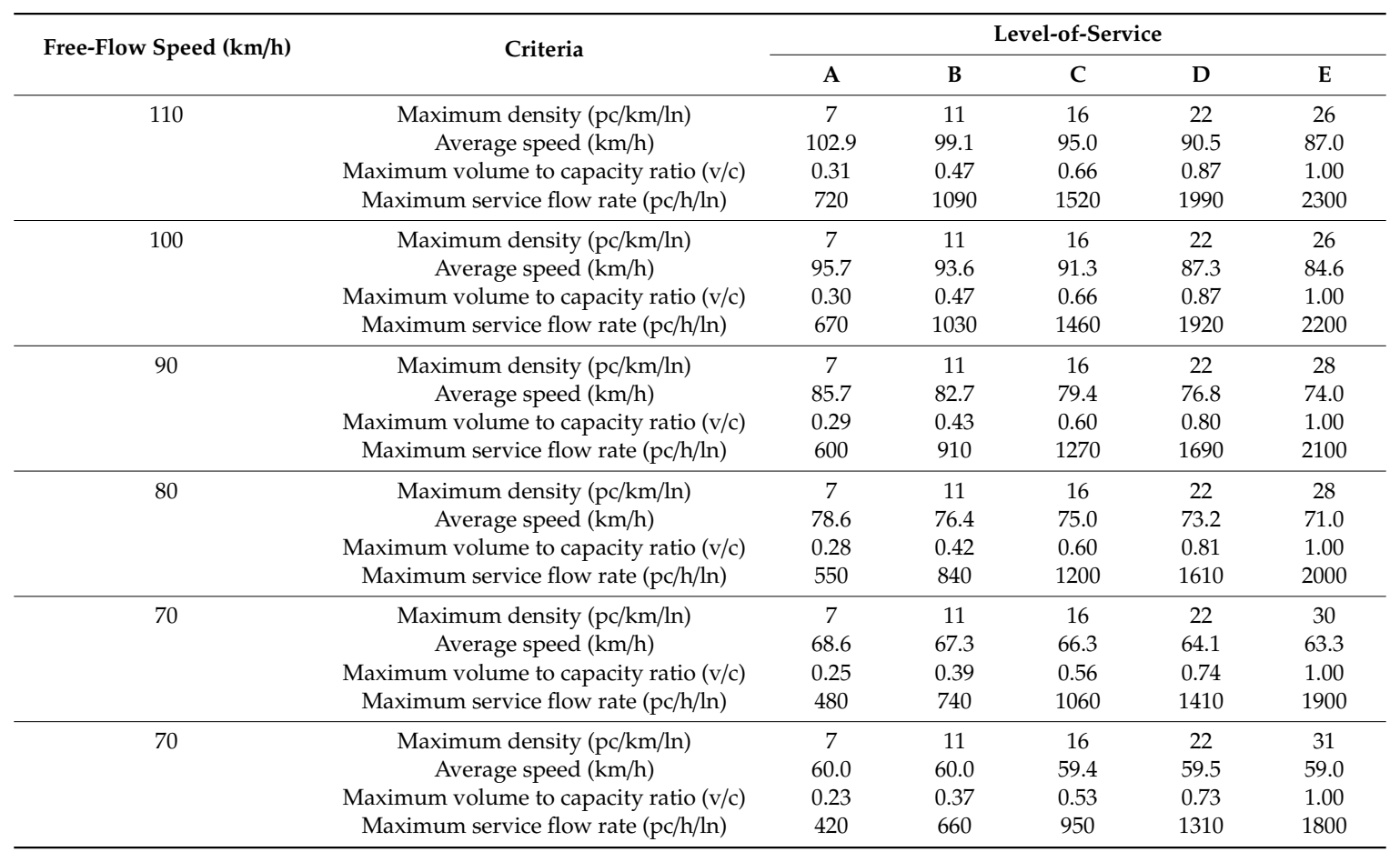

Based on the results shown in Table 11, only five lanes (Lanes 19, 41, and 58 to 60) recorded different levels-of-service between the estimated and observed free-flow speeds, while the other 59 lanes recorded the same level-of-service. Lanes 19 and 41 yielded a better level-of-service based on the estimated free-flow speeds, while Lanes 58 to 60 produced a slightly worse level-of-service due to their considerably lower estimated free-flow speed values, as this site recorded a much higher access point density of 7.43 access points $/ \mathrm{km}$ eastbound and 11.43 access points per $\mathrm{km}$ westbound compared to the other sites, which only recorded between 0.26 to 3.14 access points $/ \mathrm{km}$. This suggests that access point density is a more sensitive parameter and has the greatest impact on the estimation of free-flow speeds, as the coefficient given in the regression equation can directly estimate the reduction in free-flow speed for every access point found over $1 \mathrm{~km}$. Nevertheless, based on the $92 \%$ correctly projected level-of-service, the estimated free-flow speeds can be applied to determine the level-of-service. However, the developed model has yet to be validated. As sites suitable for data collection are limited, data recorded for all 64 lanes were used to develop the free-flow speed model. Further research will be needed to validate the developed model. As free-flow speed is the fundamental parameter needed to estimate level-of-service, an inaccurate estimation of free-flow speed will result in the incorrect determination of level-of-service. Therefore, the developed model can be used as the basis for assessing the design consistency of new and existing multilane highways to facilitate the sustainable development of road networks, particularly the inter urban multilane highways in Malaysia, as free-flow speed is the most fundamental and important parameter in determining the capacity and level-of-service of any uninterrupted road facility. 
Table 11. Comparisons of the level-of-service (LOS) between the estimated and observed free-flow speeds (FFS).

\begin{tabular}{|c|c|c|c|c|c|c|c|c|c|c|c|}
\hline \multirow{2}{*}{ Lane No. } & \multirow{2}{*}{$\mathrm{V}^{1}(\mathrm{pcu} / \mathrm{h})$} & \multicolumn{2}{|c|}{ Estimated } & \multicolumn{2}{|c|}{ Observed } & \multirow{2}{*}{ Lane No. } & \multirow{2}{*}{$\mathrm{V}^{1}(\mathrm{pcu} / \mathrm{h})$} & \multicolumn{2}{|c|}{ Estimated } & \multicolumn{2}{|c|}{ Observed } \\
\hline & & FFS $(\mathrm{km} / \mathrm{h})$ & LOS & FFS $(\mathrm{km} / \mathrm{h})$ & LOS & & & FFS $(\mathrm{km} / \mathrm{h})$ & LOS & FFS $(\mathrm{km} / \mathrm{h})$ & LOS \\
\hline 1 & 589 & 60.46 & B & 69.33 & B & 33 & 937 & 74.3 & $\mathrm{C}$ & 71.71 & $\mathrm{C}$ \\
\hline 2 & 552 & 80.58 & B & 86.65 & B & 34 & 620 & 89.94 & B & 81.06 & B \\
\hline 4 & 507 & 85.22 & $\mathrm{~A}$ & 88.58 & $\mathrm{~A}$ & 36 & 546 & 89.94 & $\mathrm{~A}$ & 85.99 & $\mathrm{~A}$ \\
\hline 5 & 467 & 77.31 & A & 80.72 & A & 37 & 424 & 74.41 & A & 81.19 & A \\
\hline 6 & 110 & 93.69 & $\mathrm{~A}$ & 102.17 & A & 38 & 222 & 90.16 & A & 97.14 & A \\
\hline 9 & 499 & 79.02 & $\mathrm{~A}$ & 75.16 & A & 41 & 744 & 77.26 & B & 70.83 & $\mathrm{C}$ \\
\hline 10 & 381 & 99.15 & A & 96.86 & A & 42 & 401 & 88.2 & A & 98.05 & A \\
\hline 11 & 567 & 78.41 & B & 80.36 & B & 43 & 660 & 70.26 & B & 74.83 & B \\
\hline 12 & 216 & 98.81 & A & 98.87 & A & 44 & 377 & 97.77 & A & 96.45 & A \\
\hline 13 & 399 & 72.86 & $\mathrm{~A}$ & 67.36 & A & 45 & 902 & 65.99 & $\mathrm{C}$ & 71.42 & C \\
\hline 14 & 191 & 89.19 & A & 79.58 & A & 46 & 776 & 80.85 & B & 90.62 & B \\
\hline 19 & 555 & 79.98 & A & 78.23 & B & 51 & 634 & 76.79 & B & 82.16 & B \\
\hline 20 & 314 & 96.66 & A & 90.88 & A & 52 & 282 & 94.28 & A & 101.3 & A \\
\hline 21 & 408 & 66.78 & $\mathrm{~A}$ & 69.79 & A & 53 & 639 & 66.73 & B & 67.57 & B \\
\hline 22 & 389 & 84.88 & A & 87.86 & A & 54 & 503 & 82.53 & A & 86.87 & A \\
\hline 23 & 409 & 61.29 & A & 71.12 & A & 55 & 1232 & 73.43 & B & 78.28 & B \\
\hline 24 & 392 & 84.01 & $\mathrm{~A}$ & 91.01 & A & 56 & 673 & 91.55 & A & 89.1 & A \\
\hline 25 & 446 & 72.98 & A & 75.09 & A & 57 & 655 & 65.35 & B & 64.2 & B \\
\hline 26 & 212 & 91.99 & A & 87.88 & A & 58 & 504 & 68.14 & B & 77.99 & A \\
\hline 27 & 344 & 74.61 & A & 70.18 & A & 59 & 649 & 47.87 & $\mathrm{C}$ & 59.97 & B \\
\hline 28 & 277 & 90.14 & A & 82.22 & A & 60 & 474 & 58.83 & B & 75.79 & A \\
\hline 29 & 335 & 75.75 & A & 65.49 & A & 61 & 388 & 67.73 & A & 74.76 & $\mathrm{~A}$ \\
\hline 30 & 353 & 73.57 & A & 77.45 & A & 62 & 167 & 84.85 & A & 95.69 & A \\
\hline 31 & 369 & 73.7 & A & 68.15 & A & 63 & 356 & 70.51 & A & 69 & A \\
\hline
\end{tabular}

\section{Conclusions}

This study, which is part of the Malaysia Highway Capacity Stage 3 to produce the Malaysia Highway Capacity Manual, is a continuous effort by the Ministry of Works Malaysia to ensure that the future designs of highways are sustainable and that analyses of transport infrastructure are made accurately and are representative of local conditions. In this study, free-flow speed models were developed and assessed based on local traffic conditions that are heterogeneous in nature. The initial statistical tests of the dataset utilizing a one-way ANOVA test, a Levene test, and a post hoc test indicated that motorcycles have significant differences compared to all other vehicles. Therefore, an alternative approach was used, where we grouped the datasets according to vehicle classifications. These groups were segregated into three categories (all vehicles, vehicles excluding motorcycles, and cars only) and three models using the three different groups of mean free-flow speeds, which were developed and tested using multiple linear regression. A comparison of these models clearly shows that the category that includes all vehicles is the best model to estimate the free-flow speed of Malaysian multilane highways. This study was concluded based on the total highest score computed from the values of the performance indicators.

The results of this study will improve our understanding of how vehicle classification affects free-flow speed and the estimation of free-flow speed for future multilane highways by applying the developed free-flow speed model. This measurement is not possible to acquire from field measurements but can be done accurately using the present method, as the free-flow speed model was developed based on local driving conditions. This will have a significant impact on the design and analysis of multilane highways, as free-flow speed is the most fundamental and important parameter to determine level-of-service. This study is one of the earliest attempts to study the effects of vehicle classes on free-flow speeds and to develop a free-flow speed estimation model for inter urban multilane highways in Malaysia. However, because the sites suitable for data collection are limited, the data recorded at 
all 16 sites were used to develop the free-flow speed model. However, due to the limitations of data collection, the developed model has yet to be validated. As such, further research will be conducted to include more sites in the analysis and to validate the developed model. This study could also be extended to investigate the effects of other factors, such as the posted speed limit, pavement conditions, and weather on the estimation of free-flow speed.

Author Contributions: Conceptualization, L.V.L.; methodology, L.V.L. and T.A.A.; software, T.A.A.; validation, L.V.L.; formal analysis, T.A.A.; investigation, T.A.A.; resources, L.V.L.; data curation, T.A.A.; writing-original draft preparation, L.V.L.; writing-review and editing, W.C.G. and M.B.M.; visualization, W.C.G. and M.B.M.; supervision, L.V.L.; project administration, L.V.L.; funding acquisition, L.V.L. All authors have read and agreed to the published version of the manuscript.

Funding: This research was funded by the Highway Planning Division, Ministry of Works Malaysia, grant number U252.

Acknowledgments: The authors wish to express their sincere gratitude to the School of Civil Engineering, Universiti Sains Malaysia, for the support.

Conflicts of Interest: The authors declare no conflict of interest.

\section{References}

1. Roads Branch, Public Works Department Malaysia. Arahan Teknik (Jalan) 8/86. A Guide on Geometric Design of Roads; Roads Branch, Public Works Department Malaysia: Kuala Lumpur, Malaysia, 1986.

2. Transportation Research Board. HCM 2010, Highway Capacity Manual (2010), Volume 2: Uninterrupted Flow; National Academy of Scences: Washington, DC, USA, 2010.

3. Dowling, R.; Kittelson, W.; Zegeer, J.; Skabardonis, A. Planning Techniques to Estimate Speeds and Service Volumes for Planning Applications. Transportation Research Board, 387. 1997. Available online: http://onlinepubs.trb.org/Onlinepubs/nchrp/nchrp_rpt_387.pdf (accessed on 28 April 2009).

4. Tseng, P.Y.; Shieh, S.L.; Lin, F.B. Estimation of free flow speeds for multilane rural and suburban highways. J. East. Asia Soc. Transp. Stud. 2005, 6, 1484-1495.

5. Bang, K.L.; Carlsson, A.; Palgunadi. Development of speed-flow relationships for Indonesian rural roads using empirical data and simulation. Transp. Res. Rec. 1996, 1484, 24-32.

6. Boora, A.; Ghosh, I.; Chandra, S.; Rani, K. Measurement of free-flow conditions on multilane intercity highways under heterogeneous traffic conditions. J. S. Afr. Inst. Civ. Eng. 2018, 60, 2-9. [CrossRef]

7. Dixon, K.K.; Wu, C.H.; Sarasua, W.; Daniel, J. Posted and free flow speed for rural multilane highways in Georgia. J. Transp. Eng. 1999, 125, 487-494. [CrossRef]

8. Deardoff, M.D.; Wiesner, B.N.; Fazio, J. Estimating Free-flow Speed from Posted Speed Limit Signs. Procedia Soc. Behav. Sci. 2011, 16, 306-316. [CrossRef]

9. Ali, A.T.; Flannery, A.; Venigalla, M.M. Prediction Models for Free Flow Speed on Urban Streets. In Proceedings of the Transportation Research Board 86th Annual Meeting, (No. 07-1954), Washington, DC, USA, 21-25 January 2007.

10. Razzaq, A.K. Model Development to Predict Free Flow Speed for Multi-Lane Highways. Res. Rev. J. Eng. Technol. 2017, 6, 1-7.

11. Figueroa, A.M.; Tarko, A.P. Speed factors on two-lane rural highways in free-flow conditions. Transp. Res. Board 2005, 1912, 39-46. [CrossRef]

12. Gong, H.; Stamatiadis, N. Operating Speed Prediction Models for Horizontal Curves on Rural Four-Lane Highways. Transp. Res. Board 2008, 2075, 1-7. [CrossRef]

13. Errampalli, M.; Senathipahti, V.; Ravinder, K.; Nataraju, J. Development of free-speed equations for assessment of road-user cost on high-speed multi-lane carriageways of India on Plain Terrain. Curr. Sci. 2011, 100, 1362-1372.

14. Nicholas, J.G.; Lester, A.H. Traffic \& Highway Engineering, 4th ed.; Cengage Learning, Inc.: Florence, KY, USA, 2008.

15. Melo, P.; Lobo, A.; Couto, A.; Rodrigues, C.M. Road cross-section width and free-flow speed on two-lane rural highways. Transp. Res. Rec. 2012, 2301, 28-35. [CrossRef]

16. Chathoth, V:; Asaithambi, G. Modeling free-flow speeds on undivided roads in mixed traffic with weak lane discipline. Transp. Res. Rec. 2018, 2675, 105-117. [CrossRef] 
17. Rao, A.M.; Rao, K.R. Free speed modeling for urban arterials-A case study on Delhi. Period. Polytech. Transp. Eng. 2015, 43, 111-119. [CrossRef]

18. Balakrishnan, S.; Sivanandan, R. Influence of lane and vehicle subclass on free-flow speeds for urban roads in heterogeneous traffic. Transp. Res. Procedia 2015, 10, 166-175. [CrossRef]

19. Balakrishnan, S.; Sivanandan, R. Developing free-flow speed models for urban roads under heterogeneous traffic conditions. Int. J. Traffic Transp. Eng. 2017, 7, 443-460.

20. Thomas, J.; Srinivasan, K.K.; Arasan, V.T. Vehicle class wise speed-volume models for heterogeneous traffic. Transport 2012, 27, 206-217. [CrossRef]

21. Sekhar, C.R.; Nataraju, J.; Velmurugan, S.; Kumar, P.; Sitaramanjaneyulu, K. Free flow speed analysis of two lane inter urban highways. Transp. Res. Procedia 2016, 17, 664-673. [CrossRef]

22. Ye, Q.; Tarko, A.P.; Sinha, K.C. A Free-Flow Speed Model for Indiana Arterial Roads. In Proceedings of the 80th Annual Transportation Research Board Meeting, Paper (No. 01-3349), Washington, DC, USA, 7-11 January 2001; pp. 189-193.

23. Leong, L.V.; Awang, M.A. Estimating Space-Mean Speed for Rural and Suburban Highways in Malaysia. J. East. Asia Soc. Transp. Stud. 2011, 9, 1474-1484.

24. Highway Planning Unit, Ministry of Works Malaysia. Malaysian Highway Capacity Manual 2011; Highway Planning Unit, Ministry of Works Malaysia: Kuala Lumpur, Malaysia, 2011; ISBN 978-967-5399-21-3.

(C) 2020 by the authors. Licensee MDPI, Basel, Switzerland. This article is an open access article distributed under the terms and conditions of the Creative Commons Attribution (CC BY) license (http://creativecommons.org/licenses/by/4.0/). 